\title{
In Vitro Release Testing of Semi-Solid Dosage Forms
}

\author{
Isadore Kanfer ${ }^{1,2,{ }^{*}, \text { Seeprarani Rath }}{ }^{3}$, Potiwa Purazi ${ }^{3}$, Nyengeterai Amanda Mudyahoto ${ }^{3}$ \\ ${ }^{1}$ Faculty of Pharmacy, Division of Pharmaceutics, Rhodes University, Grahamstown, 6140, South Africa \\ ${ }^{2}$ Leslie Dan Faculty of Pharmacy, University of Toronto, Toronto, ON, M4V 3B9, Canada \\ ${ }^{3}$ Biopharmaceutics Research Institute, Rhodes University, Grahamstown, 6140, South Africa
}

e-mail: I.Kanfer@ru.ac.za

\section{BACKGROUND}

$\mathrm{n}$ vitro release testing (IVRT) is used to monitor the release and diffusion of drug products from semisolid dosage forms (1-11) and has long been considered a valuable tool in formulation development. IVRT has also been used to screen formulations to select promising candidates, (12-16) and, importantly, accepted for use to obtain a waiver of bioequivalence studies following postapproval changes to a product (17). A comprehensive review relating to the methodology, application, and equipment used in IVRT and published results using this technique is provided in this paper.

In vitro diffusion studies were used by Tehrani et al. (12) to investigate the influence of various additives on the release of piroxicam from different topical vehicles, and they observed that the release was considerably higher in formulations containing 2-propanol caused by decreasing the viscosity of the formulation which proved to be helpful in screening the formulations for relative availability of the drug. The application of IVRT has many additional benefits such as its use in product development (18), identification of critical manufacturing variables, gauging in vivo performance, and product performance assessment including batch-batch and lot-lot uniformity (19). Its utility and value to assess the release of active pharmaceutical ingredients (APIs) from semisolid dosage forms has been reported in numerous publications (20-32).

A simple and reproducible method using vertical diffusion cell (VDC) systems and a synthetic membrane that could be readily adopted for the quality control of semisolid products was first developed and demonstrated by Shah et al. in 1989 (22). An IVRT method for assessing the release of diclofenac dimethylamine from topical gels was developed by Goebel et al. (33). A significant difference was observed between the fluxes of the tested products. These differences in the performance of topical products were thought to be due to the influence of excipients and vehicle components and, thus, highlight the influence of excipients.
The in vitro release rates of acyclovir from generic creams approved in South African and Indian markets were evaluated and compared with the innovator products available in the respective markets using VDCs in order to determine the "sameness" of those approved generic products based on the in vitro data (15). The in vitro release comparisons were based on the recommendations described in the United States Food and Drug Administration (FDA) Draft Guidance for acyclovir ointment (34) and the SUPAC-SS Guidance for nonsterile semisolid dosage forms (17). Plots of the release rates (slopes) of the cumulative amounts of acyclovir released versus the square root of time for the various generic formulations compared with the reference product were found to be within the limits of $75.00 \%$ to $133.33 \%$ with a $90 \%$ confidence interval. These experiments indicate that the generic acyclovir cream formulations exhibited release rates that were comparable to the innovator product and could be considered pharmaceutically equivalent.

Whereas dissolution testing is considered as an important test to determine the release of non-solution products which are administered via an extravascular route (generally orally) and intended for the systemic circulation, drug release from products which are topically applied to the skin is considered equally important. Topical dermatological products, usually semisolids such as creams, ointments, emulsions, foams, gels, and lotions, amongst others, are generally intended for local action on or in the skin where the drug is not destined for the systemic circulation (35). In certain instances where a transdermal dosage form is specifically intended for local action only, IVRT should be readily applicable whereas in vitro testing of transdermal dosage forms intended for systemic absorption, in vitro penetration tests (IVPT) using various types of skin samples as the membranes may be the preferred approach. However, there can be semisolids with systemic action, and there are transdermal delivery systems with local action approved by the FDA for the United States market.

Topical products intended for the systemic circulation require penetration beyond the stratum corneum and 
epidermis layers of the skin, whereas topical products used dermatologically for local action are not intended to be absorbed, and, hence, release only from such dosage forms as the major pre-requisite.

When two products with the same or similar composition (i.e., contain the same components [Q1], and the same amounts of the same components [Q2]), potential differences between the test and reference product may be due to the issues of structural dissimilarity $(\mathrm{Q} 3)$ relating to the arrangement of matter and state of molecular aggregation. Differences between such products can often be identified using IVRT since the in vitro drug release is generally a property of the drug formulation (9).

Given its acceptance as a useful tool to assess product sameness (17), IVRT is the first step towards the goal of Quality by Design which emphasizes the development of meaningful drug product specifications based on clinical performance (19). However, semisolid dosage forms are generally complex multiphase formulations where factors such as the size of the dispersed particles, interfacial tension between phases, and the rheology of the formulation, amongst others, determine the physical properties of the system (18). Although several attempts to validate IVRT methods have previously been published (36-47), none have described appropriate validation procedures relating to control the essential validation components such as VDC dimensions, system temperature, volume of receptor fluid, stirring speed, membrane compatibility, and other associated physical and operational variables to ensure reproducible and reliable results. Unlike oral drug products, there has been an absence of regulatory guidelines regarding appropriate validation procedures for the IVRT of locally acting topical products, although recently, a new FDA guideline on acyclovir cream using IVRT (48) provides some information relating to IVRT validation. Various reports have shown that alterations in IVRT method parameters can influence the results and clearly indicate that it is essential to assess the influence of each IVRT method parameter on the resulting data $(49,50)$.

Although in vitro studies have not generally found acceptance by most regulatory agencies to establish bioequivalence, draft guidances on the antiviral drug product acyclovir ointment and cream have been published by the FDA $(34,48)$. These guidances recommend the use of in vitro methodology and additional associated testing to determine the bioequivalence of acyclovir topical ointments and creams $(34,48)$.

\section{EQUIPMENT AND METHODOLOGY}

IVRT has been established as a compendial method by the USP, and the compendial apparatuses and procedures for these tests are described in the USP General Chapter $<1724>(51)$.

\section{USP Apparatus 4: Flow-Through Cell Apparatus}

In the flow-through method, the test sample is in a small volume cell through which media is pumped at a constant temperature. Upon leaving the cell, the eluate is filtered and can then be analyzed directly or collected in fractions to calculate the percent drug release (52). Several other automated and flow-through methods have also been used $(30,31,53-56)$. An "insertion cell" used in conjunction with a compendial flow-through cell (USP) has been described by Chatteraj and Kanfer (31) where the release of acyclovir from semisolid dosage forms was monitored. The results were found to compare favorably with previous acyclovir release data using different diffusion cells and indicated that their "insertion cell" offered distinct advantages compared to VDCs in that it is easier to use and readily adaptable for use with the compendial flow-through apparatus. A further advantage of this insertion cell is that, unlike other VDCs where air bubbles at the membrane/liquid interface often occur, such problems are avoided (31).

\section{Diffusion Cells}

Diffusion cells can be classified as horizontal, vertical, or flow-through based on their physical design. These cells can also be used along with numerous modifications to the basic design. The VDC, recommended by the USP, is one of the more widely accepted apparatuses for in vitro

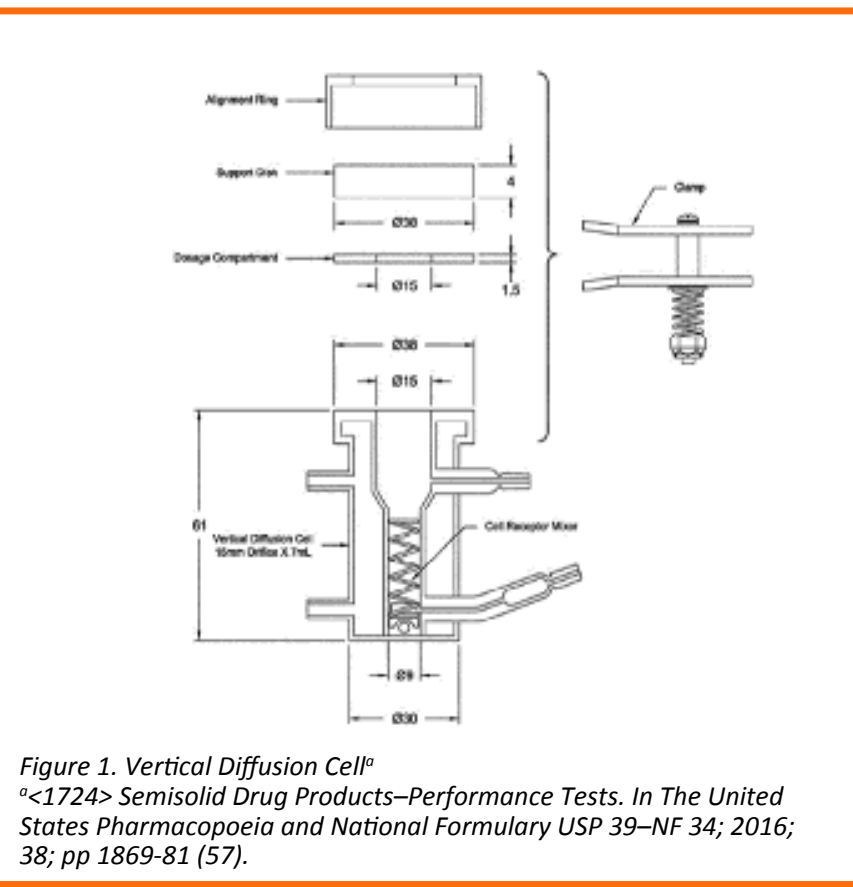


diffusion studies (19) and by far the most commonly used in vitro model for the study of drug release from topical dosage forms (57). An example of a typical VDC is shown in Figure 1.

Each VDC assembly consists of two chambers: a donor chamber and a receptor chamber. Each chamber is separated by a membrane. A layer of the semisolid product under evaluation is placed in the donor chamber on top of the membrane in contact with the receptor medium in the receptor chamber. However, a serious drawback using a VDC is the occurrence of air bubbles at the membrane-liquid interface, which is often difficult to observe. Failure to remove these air bubbles can have serious consequences relating to the precision, accuracy, and reproducibility of the resulting data. A simple diffusion cell (Figure 2) described by Chattaraj et al. (29) where the semisolid dosage form is mounted underneath the membrane as opposed to a VDC where the dosage form is placed on top of the membrane overcomes the bubble formation problem. This modus operandi prevents discontinuity occurring between the membrane and liquid interface, thereby preventing the formation of air bubbles at the membrane/liquid interface.

Gilman et al. (58) studied the impact of VDC design on IVRT and observed that the amount of drug released depends on the cell design. The release rates increased with a decrease in surface area and with an increase in cell volume.

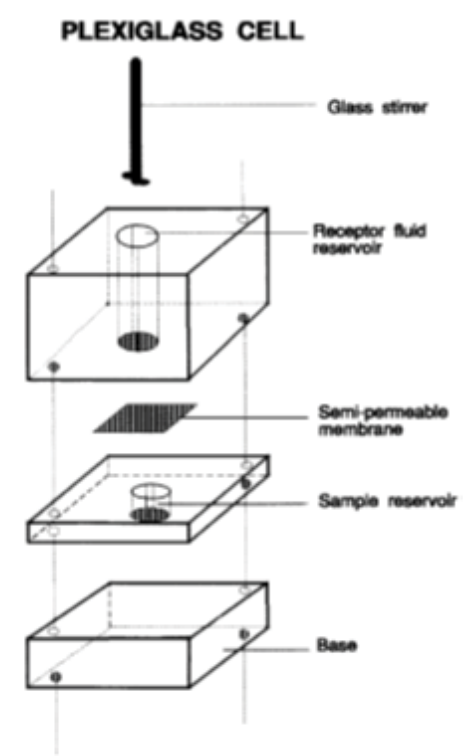

Figure 2. Simple Diffusion Cell ${ }^{a}$ ${ }^{a}$ Chattaraj, et al. Int. J. Pharm. 1995, 120 (1), 119-24 (29).

\section{Immersion Cells}

The immersion cell method is similar to the USP paddleover-disk method (51) but, in this instance, a membrane is used in the immersion cell which is placed into a USP dissolution vessel $(10,28,57,59-61)$.

\section{Membranes}

VDCs have been used with different membranes ranging from human and animal skin to synthetic membranes $(15,62,63)$. The use of skin or synthetic membranes depends on the objective of the test. Also, IVPT typically uses skin as the membrane since it is a test designed to mimic biological conditions with a finite dose exposed to the atmosphere and a biologically relevant receptor medium, whereas IVRT typically uses synthetic membranes to detect differences in batch-batch and lot-lot comparisons (64). Various synthetic membranes have been used such as cellulose acetate/nitrate/mixed ester, polysulfone, polytetrafluoroethylene, nylon, polycarbonate, Fluoropore, and Supor (18) which separate the donor compartment containing the formulation to be tested and the receptor compartment containing the appropriate receptor medium $(15,38,49,50)$.

The type of synthetic membrane used varies with the purpose of investigation. The release of hydrocortisone (HC) from two commercial creams using different microporous membranes (pure cellulose acetate, cellulose, and polysulfone) of similar sizes and thicknesses was studied by Shah et al. (22). In a study reported by $\mathrm{Ng}$ et al. (37), the diffusion rates of ibuprofen across 13 membranes were determined using VDCs, and an attempt was made to establish a correlation between the membrane thickness, pore size, and molecular weight cut-off with drug fluxes. Whereas the authors categorized the membranes into high-flux $\left(8-18 \mathrm{mg} / \mathrm{cm}^{2} / \mathrm{h}\right)$ and low-flux $\left(0.1-3 \mathrm{mg} / \mathrm{cm}^{2} / \mathrm{h}\right)$ based on their IVRT results, the drug fluxes did not show strong correlations $\left(r^{2}<0.99\right)$ with the relevant membrane characteristics. The degree of diffusional resistance to ibuprofen was greatly influenced by the type of membrane. Hence, factors such as membrane flux, thickness, coating, and others should be considered before choosing a membrane for IVRT. The membranes may be pretreated by soaking in the receptor medium or isopropyl myristate prior to IVRT $(44,65)$. However, synthetic membranes used for quality control tests should necessarily act as an inert support rather than a barrier and provide the least resistance to drug diffusion $(36,37,50)$. The selection of an appropriate membrane is crucial in the design of an appropriate IVRT, and the membrane must be compatible with the formulation and not interfere with recovery of the API $(11,53)$. 


\section{Receptor Media}

The selection of an appropriate receptor medium is very important and depends on the solubility of the API. Alcohol and/or a surfactant may be incorporated into the receptor medium if the API shows solubility issues. Whereas ideally, the weight/volume of the test formulation should reflect a typical dose of the product, it is preferable to use a partial dose rather than adding a surfactant or alcohol to the receptor medium to obtain sink conditions. A further important consideration is the $\mathrm{pH}$ of the medium, and the choice of $\mathrm{pH}$ should be based on the $\mathrm{pH}$-solubility profile of the API and the $\mathrm{pH}$ of the formulation (66). The selected receptor should permit a sufficient amount of release of API within a reasonable period (44) and sink conditions should be maintained (36). Yacobi et al. (50) evaluated various parameters (viz. receptor media, membranes, and stirring speed) that could affect the in vitro release of drugs from topical dermatological products and found that the receptor medium was the most important and critical parameter that influences the drug release from the formulations. Mitu et al. (67) assessed three ketoconazole marketed drug products and four experimental formulations, using two receptor media. A higher release was observed in the hydro-alcoholic receptor media whereas the buffer mimicking the physiological $\mathrm{pH}$ limited the diffusion process, which was attributed to the low solubility of the drug in the buffer.

Deaeration of the receptor medium is essential to prevent bubble formation at the interface with the membrane as it lowers the area of contact between the membrane and the membrane containing the test formulation leading to inconsistent results. The receptor medium should be stirred throughout the experiment at a constant stirring speed, usually with a magnetic stir bar. Various rates of stirring have been reported, such as 400,450 , and $600-$ $800 \mathrm{rpm}$ to ensure uniform mixing of the receptor phase $(9,36,68)$.

IVRT for topical semisolid products is typically carried out for six hours, and specific volumes (preferably 0.1$0.2 \mathrm{~mL}$ ) of samples are withdrawn from the receptor chamber at predetermined time intervals and replaced with fresh receptor medium. In certain instances, longer sampling times may be required, but the release of the API may deviate from linearity at extended times, and the deviation usually occurs when more than $35 \%-45 \%$ of the API has been released (10). The test temperature is usually maintained at $32 \pm 1^{\circ} \mathrm{C}$ throughout the experiment to reflect normal skin temperature (37) when a semisolid dosage form is applied to the skin. Although increased temperatures have sometimes been used $(30,44,47$, 69,70 ), the higher temperatures may result in physical changes to the formulation which may affect the release rate of the API. In a study using a cellulose membrane, the increase in temperature from $32{ }^{\circ} \mathrm{C}$ to $37{ }^{\circ} \mathrm{C}$ had a significant effect on the release of acyclovir from a cream product, probably as a result of decreasing viscosity of the formulation with increasing temperature (30). Other temperatures can be used if justified.

\section{THEORETICAL PRINCIPLES OF API RELEASE FROM SEMISOLID DOSAGE FORMS}

The kinetics of IVRT has been described by the Higuchi model $(71,72)$. This model describes the release of drug from one side of a layer in which the drug is suspended in an ointment base. It takes into account the Fickian Laws of diffusion $(73,74)$. During release from semisolid formulations, the diffusion of molecules from a region of high concentration (donor chamber) to a region of low concentration (receptor chamber) occurs (18). The membrane acts as the rate limiting step to maintain a diffusional sink. As the concentration of drug in the donor compartment decreases, the concentration of drug in the receptor medium increases.

Fick's first law is used to describe the rate of mass transfer per unit area, which is expressed as the "Flux."

$$
J=-D \frac{d C}{d x}
$$

Where:

$\mathrm{J}=$ Flux

$D=$ diffusion coefficient

$\mathrm{dC}=$ change in concentration of solute

$\mathrm{dx}=$ change in distance

Fick's second law states that the rate of change in concentration in a volume within a diffusional field is proportional to the rate of change in spatial concentration gradient at that point in time. The proportionality constant is the diffusion coefficient, expressed as:

$$
\frac{\partial C}{\partial t}=D\left[\frac{\partial^{2} c}{\partial x^{2}}+\frac{\partial^{2} c}{\partial y^{2}}+\frac{\partial^{2} c}{\partial z^{2}}\right]
$$

Where $x, y$, and $z$ are spatial coordinates.

Following the Fickian Laws of Diffusion, Higuchi has shown that for cream and certain ointment formulations (72), drug release follows a square-root of time profile, and that the release rate is proportional to the square root of the drug solubility, the exposed surface area, the 
diffusion constant, and inverse time which is based on Fick's law of diffusion. The Higuchi theory is only valid if:

(a) The percentage released is less than $30 \%$ of the total drug in the vehicle

(b) Only a single drug species is present in the vehicle

(c) The diffusion coefficient does not vary with respect to time or position within the vehicle layer

(d) Only the drug diffuses out of the vehicle

(e) The drug reaching the receptor side is removed rapidly

$$
\frac{M_{t}}{M_{0}}=K_{t}^{\frac{1}{2}}
$$

Where

$M_{t}=$ amount of drug released in time $t$

$M_{0}=$ initial amount of drug in formulation

$k=$ release rate constant

The plot of the amount of API released per unit area $\left(\mathrm{mg} / \mathrm{cm}^{2}\right)$ against the square root of time results in a straight line and its gradient is indicative of the efficiency of the active compound.

\section{EQUIPMENT AND METHOD VALIDATION}

Validation of VDC systems should include mechanical calibration and performance verification testing (PVT). Studies have recently suggested that PVT using $1 \% \mathrm{HC}$ as a part of method validation to ensure that appropriate measures have been taken to control the sources of variability in in vitro release testing (41) should be explored.

Some typical sources of variability are temperature, stirrer dimensions and stirring speed, diameter of orifice of the cell, cell capacity, bench-top levelness, and environment as well as inter- and intra-day instrument variation, inter- and intra-operator variation, and analytical and sampling procedures which need to be investigated and controlled to ensure the apparatus falls within the prescribed requirements. Physical calibration is also an important step in the validation of the IVRT method. It is conducted in the form of an apparatus qualification test which ensures the VDC system will operate correctly and provide reliable measurements and data. The apparatus qualification should be conducted preferably in compliance with specified USP recommendations $(<1724>)(51)$.
It is challenging to develop an IVRT method for semisolid dosage forms due to formulation characteristics and the specific physiological environment in which they are intended to release the API. A robust, reproducible and precise in vitro release test method was developed by Klein et al. (75) for a vaginal microbicide gel. The release testing method was sensitive to both chemical and physical changes such as the viscosity of the formulation, excipient composition, and particle size of the API. The rationale behind a performance test for a dosage form is to predict and monitor the consistency in the manufacturing process of that dosage form (69).

In order to ensure that an IVRT method is reproducible and reliable, it is important to duly validate it prior to its application for product qualification $(10,17,18,27,38$, $45,47)$. Thakker et al. (44) developed an IVRT method for retinoic acid which could differentiate the changes in the composition, manufacturing process, and viscosity of the formulations. The method could also assess the quality and sameness of drug products containing retinoic acid. The authors also suggested that the sensitivity of the method and the effect of back diffusion of alcohol from the receptor medium into the formulation placed in the donor compartment need to be determined as a part of complete method validation. Hauck et al. (46) assessed the reliability and reproducibility of vertical diffusion cells for determining release rates from semisolid dosage forms. On the basis of the consistent release-rate profiles of $\mathrm{HC}$ from a $1 \% \mathrm{HC}$ cream which have been observed and published since the development of this model over two decades ago, and despite high variability in IVRT studies, these authors suggested testing of in vitro release using VDCs and a 1\% HC cream could be considered a PVT for topical semisolid dosage forms. Furthermore, 1\% HC cream was employed as a reference to understand the effect of different soaking methods for membranes for IVRT by Klein et al. (41). Small but significant changes in the amount of drug released were observed with the reduction in the temperature. Considerable differences were observed in the amounts released depending on the hydration of the membrane and the medium used to soak the membrane. A recent report described the influence of major factors on diffusion kinetics where changes in receptor fluid composition can have a direct effect on the diffusion of the API across the membrane in a VDC and showed that the speed of stirring also influenced the diffusion process. However, a $\pm 2{ }^{\circ} \mathrm{C}$ change in temperature $\left(30^{\circ} \mathrm{C}-34^{\circ} \mathrm{C}\right)$ had little impact on the overall diffusion process (76). 
A robust and reproducible IVRT method that is adequately sensitive to highlight the differences in physicochemical and rheological characteristics of the formulation and stress conditions should be developed and properly validated. A validated method should possess the following attributes: precision; accuracy/sameness; dose proportionality; sensitivity to changes in excipient type, the amount of excipient, the size of the batch, and the method of manufacture.

\section{CONCLUSIONS}

IVRT has long been established as a valuable tool to monitor the release of API from semisolid dosage forms in the pursuit of product development, quality control, and even as a biowaiver of postapproval changes of topical products. Much interest has also been shown relating to the use of IVRT data as a surrogate procedure for use as a waiver of bioequivalence where the SUPAC guidance issued by the FDA in 1997 (17) and the draft guidances on acyclovir ointment (34) and cyclosporine ophthalmic emulsions (77) as well as the more recent guideline for acyclovir cream (48) recommending the use of IVRT provide compelling implications relating to the potential and future applications of IVRT for bioequivalence assessment of topical drug products. However, there are no existing standard approaches for ensuring the quality, reliability, and reproducibility of in vitro release data. Precision, accuracy, and reproducibility are generally dependent on various operational, equipment, and handling, and these important limitations may result in variability of data. An early document entitled "FIP/ AAPS Guidelines to Dissolution/In Vitro Release Testing of Novel/Special Dosage Forms" (70), which represented the scientific opinion of many experts, considered the use of in vitro release tests for semisolid dosage forms, amongst others, and concluded that "further method development and refinement will be needed to make the drug release test a generally applicable, robust, and valuable tool." Hence, the appropriate validation of IVRT systems are essential, and strict control of the variables is required to assure reliable results.

\section{REFERENCES}

1. Ayres, J. W.; Laskar, P. A. Diffusion of Benzocaine from Ointment Bases. J. Pharm. Sci. 1974, 63 (9), 1402-6. DOI: 10.1002/ jps.2600630915.

2. Bottari, F., Di Colo, G.; Nannipieri, E.; Saettone, M. F.; Serafini, M.F. Evaluation of a Dynamic Permeation Technique for Studying Drug-Macromolecule Interactions. J. Pharm. Sci. 1975, 64 (6), 946-9. DOI: 10.1002/jps.2600640610.

3. Bottari, F.; Di Colo, G.; Nannipieri, E.; Saettone, M. F.; Serafini, M. F. Influence of Drug Concentration on In Vitro Release of Salicylic
Acid from Ointment Bases. J. Pharm. Sci. 1974, 63 (11), 1779-83. DOI: 10.1002/jps.2600631127.

4. Bottari, F.; Di Colo, G.; Nannipieri, E.; Saettone, M. F, Serafini, M. F. Release of Drugs from Ointment Bases II: In Vitro Release of Benzocaine from Suspension-Type Aqueous Gels. J. Pharm. Sci. 1977, 66 (7), 926-31. DOI: 10.1002/jps.2600660705.

5. Chowhan, Z. T.; Pritchard, R. Release of Corticoids from Oleaginous Ointment Bases Containing Drug in Suspension. J. Pharm. Sci. 1975, 64 (5), 754-9. DOI: 10.1002/jps.2600640505.

6. Poulsen, B. J.; Young, E.; Coquilla, V.; Katz, M. Effect of Topical Vehicle Composition on the In Vitro Release of Fluocinolone Acetonide and its Acetate Ester. J. Pharm. Sci. 1968, 57 (6), 92833. DOI: 10.1002/jps.260057060.

7. Shah, V. P.; Elkins, J. S.; Williams, R. L. In vitro drug release measurement for topical glucocorticoid creams. Pharmacopeial Forum. 1993, 19 (2), 5048-60.

8. Weng, H. L; Parrott, E. L. Dissolution Apparatus for Gels. J. Pharm. Sci. 1983, 72 (2), 186-8. DOI: 10.1002/jps.2600720223.

9. Ueda, C. T.; Shah, V. P.; Derdzinski, K.; Ewing, G.; Flynn, G.; Maibach, H.; Rytting, H.; Shaw, S.; Thakker, K.; Yacobi, A. Topical and transdermal drug products. Pharmacopeial Forum. 2009, 35 (3), 750-64.

10. Zatz, J.; Segers, J. Techniques for measuring in vitro release from semisolids. Dissolution Technol. 1998, 5 (1), 3-17. DOI: 10.14227/dt050198p3.

11. Zatz, J. L. Drug Release from Semisolids: Effect of Membrane Permeability on Sensitivity to Product Parameters. Pharm. Res. 1995, 12 (5), 787-9. DOI: 10.1023/a:1016236331547.

12. Rafiee-Tehrani, M.; Mehramizi, A. In Vitro Release Studies of Piroxicam from Oil-in-Water Creams and Hydroalcoholic Gel Topical Formulations. Drug Dev. Ind. Pharm. 2000, 26 (4), 40914. DOI: $10.1081 /$ ddc-100101247.

13. Ng, S. F.; Tan, S. L. Development and in vitro assessment of alginate bilayer films containing the olive compound hydroxytyrosol as an alternative for topical chemotherapy. Int. J. Pharm. 2015, 495 (2), 798-806. DOI: 10.1016/j.ijpharm.2015.09.057.

14. Narkar, Y. Bioequivalence for Topical Products - An Update. Pharm. Res. 2010, 27, 2590-601. DOI: 10.1007/s11095-0100250-3.

15. Nallagundla, S.; Patnala, S.; Kanfer, I. Comparison of in vitro release rates of acyclovir from cream formulations using vertical diffusion cells. AAPS PharmSciTech. 2014, 15 (4), 994-9. DOI: 10.1208/s12249-014-0130-y.

16. Deo, S. S.; Inam, F.; Karmarkar, N. P. Analytical method development for determination of performance of adapalene in adapalene $0.1 \%$ gel formulation using manual diffusion cell. Chem. Sci. Trans. 2013, 2 (1), 251-7. DOI: 10.7598/cst2013.337.

17. SUPAC-SS: Nonsterile Semisolid Oral Dosage Forms, Scale-Up and Post approval Changes: Chemistry, Manufacturing, and Controls; In Vitro Dissolution Testing and In Vivo Bioequivalence Documentation; Guidance for Industry. U.S. Department of Health and Human Services, Food and Drug Administration, 
Center for Drug Evaluation and Research (CDER), U.S.Government Printing Office: Washington, DC; 1997.

18. Olejnik, A.; Goscianska, J.; Nowak, I. Active Compounds Release from Semisolid Dosage Forms. J. Food Drug. Anal. 2012, 101 (11), 4032-45. DOI: 10.1002/jps.23289.

19. Chang, R.; Raw, A.; Lionberger, R.; Yu, L. Generic Development of Topical Dermatologic Products: Formulation Development, Process Development, and Testing of Topical Dermatologic Products. AAPS J. 2013, 15 (1), 41-52. DOI: 10.1208/s12248012-9411-0.

20. Behme, R. J.; Kensler, T. T.; Brookex, D. A New Technique for Determining In Vitro Release Rates of Drugs From Creams. J. Pharm. Sci. 1982, 71 (11), 1303-5. DOI: 10.1002/jps.2600711133.

21. Skelly, J. P.; Shah, V. P.; Maibach, H. I.; Guy, R. H.; Wester, R. C.; Flynn, G.; Yacobi, A. FDA and AAPS Report of the Workshop on Principles and Practices of In Vitro Percutaneous Penetration Studies: Relevance to Bioavailability and Bioequivalence. Pharm. Res. 1987, 4 (3), 265-7. DOI: 10.1023/a:1016428716506.

22. Shah, V.P.; Elkins, J.; Lam, S. Y.; Skelly, J. P. Determination of in vitro drug release from hydrocortisone creams. Int. J. Pharm. 1989, 53 (1), 53-9. DOI: 10.1016/0378-5173(89)90361-x.

23. Tuomi, A.; Turakka, L.; Raty, T.; Lehmussaari, K. Release of hydrocortisone from topical semisolid preparations using three different in vitro methods. Acta Pharm. Fenn. 1989, 98, 93-9.

24. Velissaratou, A. S.; Papaioannou, G. In vitro release of chlorpheniramine maleate from ointment bases. Int. J. Pharm. 1989, 52 (1), 83-6. DOI: 10.1016/0378-5173(89)90092-6.

25. Rahman, M. S.; Babar, A., Patel, N. K.; Plakogiannis, F. M. Medicament Release From Ointment Bases: V. Naproxen In-Vitro Release and In-Vivo Percutaneous Absorption In Rabbits. Drug Dev. Ind. Pharm. 1990, 16 (4), 651-72. DOI: 10.3109/03639049009104409

26. Jamoulle, J. C.; Watts, O.; Martin, B.; Brzokewicz, A.; Shroot, B. Approach to the quality control of topical application forms. In: Scott, R. C.; Guy, R. H.; Hadgraft, J., editors. Prediction of Percutaneous Penetration, Methods, Measurements, Modelling. IBC Technical Services: London, 1990. pp 140-7.

27. Kundu, S. C.; Cameron, A. D.; Meltzer, N. M.; Quick, T. W. Development and Validation of Method for Determination of In Vitro Release of Retinoic Acid from Creams. Drug Dev. Ind. Pharm. 1993, 19 (4), 425-38. DOI: 10.3109/03639049309063200.

28. Kumar, P.; Sanghvi, P.; Collins, C. C. Comparison of Diffusion Studies of Hydrocortisone Between the Franz Cell and the Enhancer Cell. Drug Dev. Ind. Pharm. 1993, 19 (13), 1573-85. DOI: 10.3109/03639049309069327.

29. Chattaraj, S.C.; Swarbrick, J.; Kanfer, I. A simple diffusion cell to monitor drug release from semi-solid dosage forms. Int. J. Pharm. 1995, 120 (1), 119-24. DOI: 10.1016/0378-5173(94)00426-6.

30. Chattaraj, S.C.; Kanfer, I. Release of acyclovir from semi-solid dosage forms: A semi-automated procedure using a simple plexiglass flow-through cell. Int. J. Pharm. 1995, 125 (2), 215-22. DOI: 10.1016/0378-5173(95)00126-4.
31. Chattaraj, S.C.; Kanfer, I. "The insertion cell”: A novel approach to monitor drug release from semi-solid dosage forms. Int. J. Pharm. 1996, 133 (1), 59-63. DOI: 10.1016/0378-5173(95)04410-8.

32. Chattaraj, S. C.; Das, S. K.; Kanfer, I. In Vitro Release of Acyclovir from Semisolid Dosage Forms: Effect of Cyclodextrin and Polyethylene Glycol. Pharm. Dev. Technol. 1998, 3 (4), 565-70. DOI: 10.3109/10837459809028639.

33. Goebel, K.; Sato, M. E.O.; de Souza, D. F.; Murakami, F. S.; Andreazza, I. F. In vitro release of diclofenac diethylamine from gels: Evaluation of generic semisolid drug products in Brazil. Brazilian J. Pharm. Sci. 2013, 49 (2), 211-9. DOI: 10.1590/s198482502013000200003.

34. Draft Guidance on Acyclovir. U.S. Food and Drug Administration Web site. 2005. http://www.fda.gov/downloads/drugs/ guidancecomplianceregulatoryinformation/guidances/ ucm296733.pdf (accessed July 5, 2017).

35. Shah, V. P.; Williams, R.L. Importance of In Vitro Drug Release. In: Shah, V.P.; Maibach, H.I.; Jenner, J.; eds. Topical Drug Bioavailability, Bioequivalence, and Penetration. Springer New York: New York, 2014; pp 61-7. DOI: 10.1007/978-1-4939-12896 . 4.

36. Shah, V. P.; Elkins, J. S.; Williams, R. L. Evaluation of the test system used for in vitro release of drugs for topical dermatological drug products. Pharm. Dev. Technol. 1999, 4 (3), 377-85. DOI: 10.1081/pdt-100101373.

37. Ng, S. F.; Rouse, J.; Sanderson, D.; Eccleston, G. A Comparative study of transmembrane diffusion and permeation of ibuprofen across synthetic membranes using franz diffusion cells. Pharmaceutics. 2010, 2 (2), 209-23. DOI: 10.3390/ pharmaceutics2020209.

38. Ng, S. F.; Rouse, J. J.; Sanderson, F. D.; Meidan, V.; Eccleston, G. M. Validation of a Static Franz Diffusion Cell System for In Vitro Permeation Studies. AAPS PharmSciTech. 2010, 11 (3), 1432-41. DOI: 10.1208/s12249-010-9522-9.

39. Desmedt, B.; Courselle, P.; De Beer, J. O.; Rogiers, V.; Deconinck, E.; De Paepe, K. In vitro Dermal Absorption: Sample Application and Seal Quality in a Franz Diffusion Cell System. Skin Pharmacol. Physiol. 2015, 28 (5), 245-9. DOI: 10.1159/000375321.

40. Klein, S. Influence of different test parameters on in vitro drug release from topical diclofenac formulations in a vertical diffusion cell setup. Pharmazie. 2013, 68, 565-71. DOI: 10.1691/ ph.2013.6528.

41. Klein, R. R.; Bechtel, J. L.; Burchett, K.; Thakker, K. D. Technical Note: Hydrocortisone as a Performance Verification Test Reference Standard for In Vitro Release Testing. Dissolution Technol. 2010, 37-8. DOI: 10.14227/dt170410p37.

42. Lusina Kregar, M.; Dürrigl, M.; Rožman, A.; Jelčić, Ž.; CetinaČižmek, B.; Filipović-Grčić, J. Development and validation of an in vitro release method for topical particulate delivery systems. Int. J. Pharm. 2015, 485 (1), 202-14. DOI: 10.1016/j. ijpharm.2015.03.018.

43. Sesto Cabral, M. E.; Ramos, A. N.; Cabrera, C. A.; Valdez, J. C.; 
González, S. N. Equipment and method for in vitro release measurements on topical dosage forms. Pharm. Dev. Technol. 2015, 20 (5), 619-25. DOI: 10.3109/10837450.2014.908308.

44. Thakker, K. D.; Chern, W. H. Development and validation of in vitro release tests for semisolid dosage forms- case study. Dissolution Technol. 2003, 10 (2), 10-5. DOI: 10.14227/dt100203p10.

45. Parera Morell, J.L.; Contreras Claramonte, M. D.; Parera Vialard, A. Validation of a release diffusion cell for topical dosage forms. Int. J. Pharm. 1996, 137 (1), 49-55. DOI: 10.1016/03785173(95)04421-3.

46. Hauck, W. W.; Shah, V. P.; Shaw, S. W. Ueda, C. T. Reliability and reproducibility of vertical diffusion cells for determining release rates from semisolid dosage forms. Pharm. Res. 2007, 24 (11), 2018-24. DOI: 10.1007/s11095-007-9329-x.

47. Corbo, M.; Schultz, T. W.; Wong, G. K.; Van Buskirk, G. A. Development and validation of in vitro release testing methods for semisolid formulations. Pharm. Tech. 1993, 112-28.

48. Draft Guidance on Acyclovir. U.S. Food and Drug Administration Web site. 2016. http://www.fda.gov/downloads/Drugs/ GuidanceComplianceRegulatoryInformation/Guidances/ UCM428195.pdf (accessed July 5, 2017).

49. Ng, S. F.; Rouse, J. J.; Sanderson, F. D.; Eccleston, G. M. The relevance of polymeric synthetic membranes in topical formulation assessment and drug diffusion study. Arch. Pharm. Res. 2012, 35 (4), 579-93. DOI: 10.1007/s12272-012-0401-7.

50. Yacobi, A.; Shah, V. P.; Bashaw, E.D.; Benfeldt, E.; Davit, B.; Ganes, D.; Ghosh, T.; Kanfer, I.; Kasting, G. B.; Katz, L.; Lionberger, R.; Lu, G. W.; Maibach, H. I.; Pershing, L. K.; Rackley, R. J.; Raw, A.; Shukla, C. G.; Thakker, K.; Wagner, N.; Zovko, E.; Lane, M. E. Current Challenges in Bioequivalence, Quality, and Novel Assessment Technologies for Topical Products. Pharm. Res. 2014, 31, 83746. DOI: 10.1007/s11095-013-1259-1.

51. <1724> Semisolid Drug Products - Performance Tests. In The United States Pharmacopoeia and National Formulary USP 37-NF 32; The United States Pharmacopoeial Convention, Inc.: Rockville, MD, 2014, pp 1273-84.

52. CE 7smart USP Apparatus 4 - Flow Through Cell Dissolution from SOTAX. Product Center. American Pharmaceutical Review Web site. http://www.americanpharmaceuticalreview.com/25255Dissolution-Testing-Analysis-Equipment/5821525-CE-7-i-smarti-USP-Apparatus-4-Flow-Through-Cell-Dissolution/ (accessed July 7, 2017).

53. Shah, V. P.; Elkins, J.; Shaw, S.; Hanson, R. In Vitro Release: Comparative Evaluation of Vertical Diffusion Cell System and Automated Procedure. Pharm. Dev. Technol. 2003, 8 (1), 97102. DOI: $10.1081 /$ pdt-120017528.

54. Rolland, A.; Demichelis, G.; Jamoulle, J. C.; Shroot, B. Influence of Formulation, Receptor Fluid, and Occlusion, on in Vitro Drug Release from Topical Dosage Forms, Using an Automated FlowThrough Diffusion Cell. Pharm. Res. 1992, 9 (1), 82-6. DOI: 10.1023/a:1018935912097.

55. Martin, B.; Watts, O.; Shroot, B.; Jamoulle, J. A new diffusion cell - an automated method for measuring the pharmaceutical availability of topical dosage forms. Int. J. Pharm. 1989, 49 (1), 63-8. DOI: 10.1016/0378-5173(89)90153-1.

56. Shah, V. P.; Elkins, J.; Hanus, J.; Noorizadeh, C.; Skelly, J. P. In Vitro Release of Hydrocortisone from Topical Preparations and Automated Procedure. Pharm. Res. 1991, 8 (1), 55-9. DOI: 10.1023/a:1015826205930.

57. <1724> Semisolid Drug Products-Performance Tests. In The United States Pharmacopoeia and National Formulary USP 39-NF 34; The United States Pharmacopeial Convention, Inc.: Rockville, MD, 2016; 38; pp 1869-81.

58. Gilman, R. E.; Gaddam, S.; Thorpe, T.; Vonguru, J.; Klein, R. R.; Thakker, K. D.; Mattocks, D. M. Impact of Vertical Diffusion Cell Designs on In Vitro Release Rate Testing. AAPS. 2015, p 174.

59. Vankel Technology Group Buyer's Guide. 2005. p 37.

60. Corbo M. Techniques for conducting in vitro release studies on studies on semisolid formulations. Dissolution Technol. 1995, 2 (1), 3-6. DOI: 10.14227/dt020195p3.

61. Rege, P.R.; Vilivalam, V. D.; Collins, C. C. Development in release testing of topical dosage forms: use of the Enhancer CellTM with automated sampling. J. Pharm. Biomed. Anal. 1998, 17 (8), 1225-33. DOI: 10.1016/s0731-7085(97)00184-2.

62. Franz, T.J.; Lehman, P. A.; Raney, S. G. Use of Excised Human Skin to Assess the Bioequivalence of Topical Products. Skin Pharmacol. Physiol. 2009, 22 (5), 276-86. DOI: 10.1159/000235828.

63. Christensen, J. M.; Chuong, M. C.; Le, H.; Pham, L.; Bendas, E. Hydrocortisone Diffusion Through Synthetic Membrane, Mouse Skin, and EpidermTM Cultured Skin. Arch Drug Inf. 2011, 4 (1), 10-21. DOI: 10.1111/j.1753-5174.2010.00033.x.

64. Heaney, J. White paper, Diffusion Method Development Guidelines. Hanson Research Corporation: Chatsworth, CA, USA; 2014, pp 1-13.

65. Clément, P.; Laugel, C.; Marty, J. P. Influence of three synthetic membranes on the release of caffeine from concentrated W/O emulsions. J. Control. Release. 2000, 66 (2), 243-54. DOI: 10.1016/s0168-3659(99)00276-x.

66. van Amerongen, I. A.; De Ronde, H. A. G.; Klooster, N. T. M. Physical-chemical characterization of semisolid topical dosage form using a new dissolution system. Int. J. Pharm. 1992, 86 (1), 9-15. DOI: 10.1016/0378-5173(92)90025-w.

67. Mitu, M.; Lupuliasa, D.; Dinu-Pirvu, E.; Radulescu, F.; Miron, S.; Vlaia, L. Ketoconazole in Topical Pharmaceutical Formulations. The Influence of the Receptor Media on the In vitro Diffusion Kinetics. Farmacia. 2011, 59 (3), 358-66.

68. Penzes, T.; Blazso, G.; Aigner, Z.; Falkay, G.; Eros, I. Topical absorption of piroxicam from organogels - in vitro and in vivo correlations. Int. J. Pharm. 2005, 298, 47-54. DOI: 10.1016/j. ijpharm.2005.03.013.

69. Csóka, I.; Csányi, E.; Zapantis, G.; Nagy, E.; Fehér-Kiss, A.; Horváth, G.; Blazsó, G.; Erös, I. In vitro and in vivo percutaneous absorption of topical dosage forms: case studies. Int. J. Pharm. 2005, 291 (1), 11-9. DOI: 10.1016/j.ijpharm.2004.07.038. 
70. Aiache, J.; Aoyagi, N.; Bashaw, D.; Brown, C.; Brown, W.; Burgess, D.; Crison, J.; DeLuca, P.; Djerki, R.; Dressman, J.; Foster, T.; Gjellan, K.; Gray, V.; Hussain, A.; Ingallinera, T.; Klancke, J.; Kraemer, J.; Kristensen, H.; Kumi, K.; Leuner, C.; Limberg, J.; Loos, P.; Margulis, L.; Marroum, P.; Moeller, H.; Mueller, B.; Mueller-Zsigmondy, M.; Okafo, N.; Ouderkirk, L.; Parsi, S.; Qureshi, S.; Robinson, J.; Shah, V.; Siewert, M.; Uppoor, R.; Williams, R. FIP / AAPS Guidelines to Dissolution / In Vitro Release Testing of Novel / Special Dosage Forms. AAPS PharmSciTech. 2003, 4 (1), 43-52. DOI: 10.1208/ pt040107.

71. Higuchi, T. Rate of Release of Medicaments from Ointment Bases Containing Drugs in Suspension. J. Pharm. Sci. 1961, 50 (10), 874-5. DOI: 10.1002/jps.2600501018.

72. Higuchi, T. Physical chemical analysis of percutaneous absorption process from creams and ointments. J. Soc. Cosmet. Chem. 1960, 11, 85-97.

73. Martin, A.; Bustamante, P.; eds. Physical Pharmacy: Physical
Chemical Principles in the Pharmaceutical Sciences. 4th ed. Lea \& Febiger: USA, 1993.

74. Troy, D. B.; Beringer, P.; eds. Remington: The Science and Practice of Pharmacy. 21st ed. Lipincott Williams \& Wilkins: Baltimore, MA and Philadelphia PA, USA, 2006.

75. Klein, R. R.; Tao, J. Q.; Wilder, S.; Burchett, K.; Bui, Q.; Thakker, K. D. Development of an In Vitro Release Test ( IVRT ) for a Vaginal Microbicide Gel. Dissolution Technol. 2010, 17 (4), 6-10. DOI: 10.14227/dt170410p6.

76. Naik, P.; Shah, S. M.; Heaney, J.; Hanson, R.; Nagarsenker, M. S. Influence of test parameters on release rate of hydrocortisone from cream: Study using vertical diffusion cell. Dissolution Technol. 2016, 23 (3), 14-20.

77. Draft Guidance on Cyclosporine [Internet]. U.S. Food and Drug Administration Web site. 2013. http://www.fda.gov/downloads/ drugs/guidancecomplianceregulatoryinformation/guidances/ ucm358114.pdf (accessed July 6, 2017). 